\title{
Impacts of 'Teachers' Competency on Job Performance in Research Universities with Industry Characteristics: Taking Academic Atmosphere as Moderator
}

\author{
Anguo $\mathrm{Xu}^{1}$, Long $\mathrm{Ye}^{2}$ \\ ${ }^{1}$ Human Resource Office, Beijing Jiaotong University (China) \\ ${ }^{2}$ School of Economics and Management, Beijing Jiaotong University (China) \\ agxu@bjtu.edu.cn,dragon0620@,sina.com
}

Received: September 2014

Accepted: November 2014

\section{Abstract:}

Purpose: Research universities with industry characteristics play an irreplaceable role in national economic development and social development. With the rapid development of research universities with industry characteristics in China, these universities face new challenges in managing teachers and promoting their quality. This paper aims to examine the impact of teachers' competency on job performance in research universities with industry characteristics

Design/methodology/approach: Based on the behavioral event interview and questionnaire methods, a four-dimension (i.e. basic quality, teaching ability, industry awareness and research capacity) competency model was proposed, the influence mechanism of competency on job performance was examined using empirical research.

Findings: We found that there exists a significant positive correlation between the teachers' competency level, four dimensions and job performance in research universities with industry characteristics, especially between research capacity, teaching ability, industry awareness and job performance. And academic atmosphere plays a regulatory role in the interaction between the competency and job performance. 
Practical implications: Our findings can help to improve the management level of teachers in research universities with industry characteristics.

Originality/value: The paper introduces the competency theory to the teacher management in research universities with industry characteristics, and gives some interesting findings.

Keywords: industry characteristics, research universities, competency; job performance, academic atmosphere

\section{Introduction}

Research universities with industry characteristics are important component parts of the high level research oriented universities; they have characteristics of both industry characteristic universities and research universities. In other words, they have characteristics of hierarchic and classified development like research universities, and salient features and advantages of their own. Research universities with industry characteristics play an irreplaceable role in national economic development and social development. They are bases training high-quality industry talents, providing technical support for the development of industry science and technology, promoting the emergence, development and perfection of industry creative theories. However, since these research universities with industry characteristics were limited to some specific industries for a long time, the target and orientation, concept and awareness, mechanism and measures of the teaching staff construction are still in traditional human resource management stage, which obviously is unable to adapt properly to the university teacher management in knowledge economy. Therefore, new theory and methods should be introduced to it.

As an important part of the human resource development and management system, the competency theory becomes an important tool of human resource management. This paper proposes a new university teacher competency model for research universities with industry characteristics, which can be used to evaluate the job performance, and examines the influence of teachers' competency on job performance. The findings can help to inspirit teachers, improve the teachers' employment, evaluation, training, and promote the teachers' quality and the total performance.

\section{Related Theories and Research Hypothesis}

There is no generally accepted definition of competency yet, but Spencer, McClelland and Spencer (1994)'s definition is accepted by many researchers: Competency can be measured by 
an effective method, and the competency can classify teachers as excellent ones and ordinary ones, it includes motivation, attitude, self-concept, values, knowledge, and perceptible skill training and individual trait.

A competency model is a group of outstanding performance required by a particular job, which includes several competencies and depicts a unique combination of knowledge, skills and characteristics in order to complete effectively a particular job. The iceberg model and the onion model are the two important competency models. The methods to build a competency model include behavioral event interview, key event interview, work analysis, 360 degree evaluation method, expert panel discussion, and questionnaire. Although there are many researches on competency, competency models and their applications in the third industry and IT, the research on the teachers in research universities with industry characteristics is sparse.

Many researchers believe that competency is one of the determinants in performance. Using factor analysis and the structural equation method, Wang and Chen (2002) found that managerial traits, managerial skills of managers have a close relation to job performance. Song (2008) examined the relationship between competency and job performance of teachers in colleges and universities, and found that interpersonal interaction, virtues, knowledge and skill show statistically significant effects in predicting job performance, and interpersonal interaction, knowledge and skill show statistically significant effects in predicting taskperformance; interpersonal interaction and virtues show statistically significant effects in predicting job-dedication and interpersonal-facilitation. There is no significant correlation between competency and each factor of job performance, but competency may predict taskperformance and contextual performance. Researchers examined the influence of job performance based on different factors of competency, and some researchers examined the influence of competency on job performance from dynamic perspective by introducing intermediate variables.

Some researchers believe that some factors such as academic atmosphere and organizational atmosphere play a regulatory role in competency and job performance. Academic atmosphere determines the quality of training academic talent, and affects teachers' performance. By empirical study of police patrol officers in the eastern United States, Armeli, Eisenberger, Fasolo and Lynch (1998) found that the socioemotional needs affects the relationship between perceived organizational support and work performance. Zhou (2005) found that organizational atmosphere and supervisory affective commitment play a median role between the perceived organizational support and work outcomes. Ma, Liu and Fan (2012) examined the university-industry cooperation to explore the impact on the academic team core ability, they found that university-industry cooperation has a positive impact on the academic team building, also on the team formalization and learning ability. 
Following the previous research, the teachers' competency in this paper includes basic quality, teaching ability, industry awareness and research capacity. Based on the above analysis, we propose the following hypothesis $\mathrm{H}$.

H: Academic atmosphere plays a regulatory role in the interaction between the teachers' competency and job performance;

Ha: Academic atmosphere plays a regulatory role in the interaction between the basic quality and job performance;

$\mathrm{Hb}$ : Academic atmosphere plays a regulatory role in the interaction between the industry awareness and job performance;

Hc: Academic atmosphere plays a regulatory role in the interaction between the research capacity and job performance;

Hd: Academic atmosphere plays a regulatory role in the interaction between the teaching ability and job performance.

\section{Research design}

\subsection{Sample selecting}

We selected several representative industries, and chosen 1 or 2 high level research universities with industry characteristics from each industry, such as Beijing Jiaotong University, China Agricultural University, China University of Mining Technology, China University of Geosciences, University of Science Technology Beijing, Beihang University, Beijing University of Posts and Telecommunications, Beijing University of Chemical Technology.

\subsection{Measuring the controlled variables}

\subsubsection{Measurement of the job performance}

Based on the analysis of teaching jobs and consulting personnel specialist in research universities with industry characteristics and KPI, we design a job performance table, which includes 6 indexes in the three dimensions (i.e., teaching performance, research performance and profession services), and each dimension is divided into behavior and outcome. The value of each index ranges from 0 to 5 . We invited superintendents and colleagues from 8 universities to evaluate 240 teachers' competency and job performance. These teachers have different professional titles and different professional background. 


\subsubsection{Measurement of the academic atmosphere}

We will use the indexes in Deng (2009) to evaluate the academic atmosphere. Our questionnaire includes 26 indexes in the three dimensions (i.e., organizational factor, individual factor and environmental factor). We use Likert scale to evaluate the value of each index. 320 questionnaires were sent out, and 262 questionnaires are valid, the rate of callback is $87.9 \%$.

\subsection{Methodology}

The methodology is as Figure 1. Based on the proposed competency model, we first examine the relationship between the teachers' competency and their job performance in research universities with industry characteristics. Then, we investigate the impact of teachers' competency on their job performance.

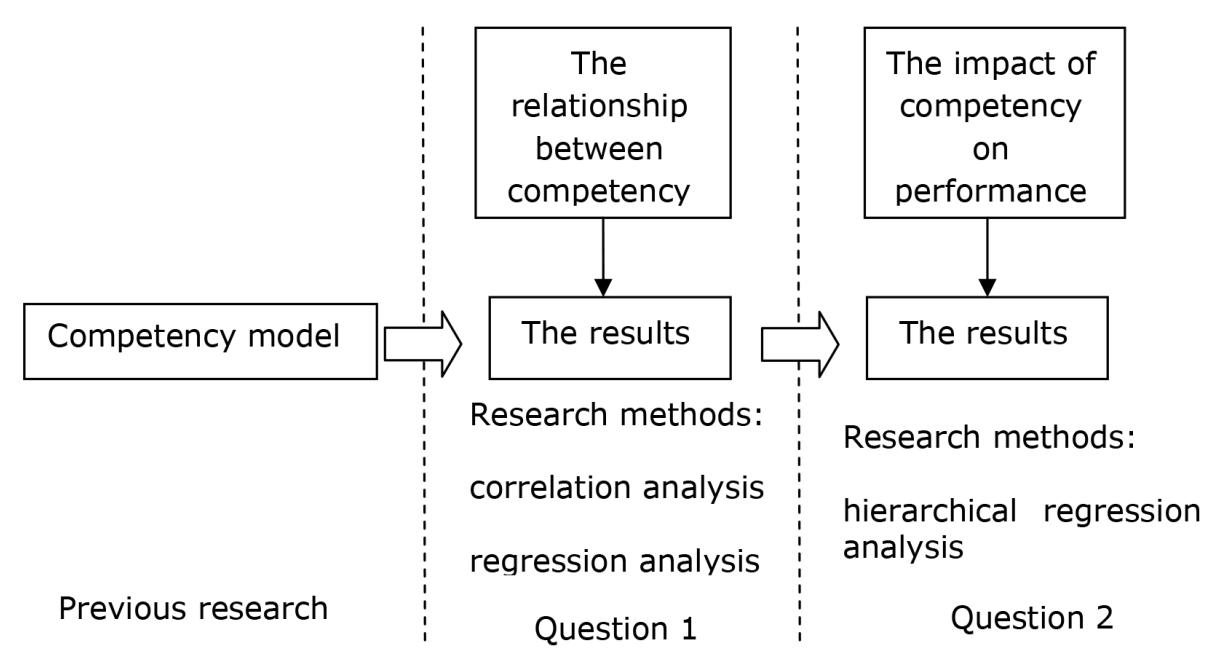

Figure 1. Research methods

\section{Results}

\subsection{Correlation analysis}

In this section, we examine the correlation between competency and job performance in research universities with industry characteristics using SPSS. The results are summarized in Table 1. From Table 1, we found that:

1. Teaching performance has significant positive correlation with competency integral level, industry awareness, basic quality and teaching ability. And However, although 
there exists a positive correlation between teaching performance and research capacity, it is not significant.

2. Research performance has significant positive correlation with competency integral level, research ability, industry awareness and basic quality, and there exists a positive correlation between research performance and teaching ability, but not significant.

3. There exists a significant positive correlation between profession service performance and competency integral level, teaching ability, research ability, and industry awareness. Although there also exists a positive correlation between profession service performance and basic quality, but not significant.

4. Job performance has significant positive correlation with teachers' competency integral level and each dimension in research universities with industry characteristics.

\begin{tabular}{|l|l|l|l|l|c|}
\hline & $\begin{array}{c}\text { Teaching } \\
\text { ability }\end{array}$ & $\begin{array}{c}\text { Industry } \\
\text { awareness }\end{array}$ & $\begin{array}{c}\text { Basic } \\
\text { quality }\end{array}$ & $\begin{array}{c}\text { Research } \\
\text { ability }\end{array}$ & Competency \\
\hline Teaching performance & $0.458^{*}$ & $0.524^{* *}$ & $0.675^{* *}$ & 0.376 & $0.623^{* *}$ \\
\hline Research performance & 0.308 & $0.354^{* *}$ & $0.474^{* *}$ & $0.557^{* *}$ & $0.570^{* *}$ \\
\hline profession service performance & $0.454^{*}$ & $0.354^{* *}$ & 0.383 & $0.586^{* *}$ & $0.570^{* *}$ \\
\hline Job performance & $0.445^{*}$ & $0.557^{* *}$ & $0.509^{* *}$ & $0.443^{* *}$ & $0.525^{* *}$ \\
\hline
\end{tabular}

Note: ${ }^{*} \mathrm{P}<0.05,{ }^{* *} \mathrm{P}<0.01$

Table 1. Correlation analysis between competency and job performance

\subsection{Regression analysis}

Taking four factors of competency (basic quality, teaching ability, industry awareness and research capacity) as predictive variables, we performed a regression analysis to decide the job performance. The results are summarized in Table 2 . The multiple correlation coefficient is $R=0.628$, and each factor of competency can jointly explain $40.1 \%$ of the total variance of job performance. We found that research capacity, teaching ability, and industry awareness are excellent predictors of competency integral level. However, basic quality cannot significantly forecast competency integral level.

\begin{tabular}{|l|l|c|c|c|c|c|}
\hline $\begin{array}{l}\text { Dependent } \\
\text { variable }\end{array}$ & $\begin{array}{l}\text { Independent } \\
\text { variable }\end{array}$ & $\begin{array}{l}\text { Regression } \\
\text { coefficient }\end{array}$ & T-value & F-value & R & $\mathbf{R}^{2}$ \\
\hline \multirow{3}{*}{ Job performance } & Research capacity & 0.440 & $3.976^{* *}$ & & \\
\cline { 2 - 4 } & Teaching ability & 0.303 & $2.462^{* *}$ & \multirow{2}{*}{28.936} & \multirow{2}{*}{0.628} & 0.410 \\
\cline { 2 - 4 } & Industry awareness & 0.018 & $2.289^{* *}$ & $\mathrm{P}=0.000$ & & \\
\cline { 2 - 5 } & Basic quality & 0.123 & 1.524 & & & \\
\hline
\end{tabular}

Note: ${ }^{*} \mathrm{P}<0.05,{ }^{* *} \mathrm{P}<0.01, n=264$.

Table 2. Regression analysis on competency and job performance 


\subsection{Mechanism analysis}

Taking job performance as dependent variable, each factor of competency as independent variable, academic atmosphere as regulated variable, we examined the regulatory role in the interaction between the competency and job performance using the hierarchical regression analysis in Wen and Hou (2004). In order to avoid the effect of colinearity, we used a normalization method to the related data. The results are summarized in Table 3.

As shown in Table 3, taking demographical variable as controlled variable, and incorporating basic quality, teaching ability, industry awareness, research capacity, and academic atmosphere into regression equation, we can significantly increase the interpretative ability of competency on the regression equation of performance $\left(\triangle R^{2}=0.079, P<0.001\right)$. The industry awareness of competency and research capacity are excellent predictors of job performance $(\beta=0.282, \mathrm{P}<0.01 ; \beta=0.341, \mathrm{P}<0.01)$, but basic quality, teaching ability, and academic atmosphere are not excellent predictors of job performance, which does not support these assumptions $\mathrm{Ha}$ and $\mathrm{Hd}$.

\begin{tabular}{|c|c|c|c|c|}
\hline Procedure & Variables & Model 1 & Model 2 & Model 3 \\
\hline \multirow[t]{4}{*}{ Step 1} & age & -0.010 & -0.183 & -0.147 \\
\hline & working age & -0.057 & -0.084 & -0.096 \\
\hline & education background & -0.021 & -0.025 & -0.046 \\
\hline & specialty & 0.066 & 0.035 & 0.034 \\
\hline \multirow[t]{5}{*}{ Step 2} & basic quality & & 0.043 & 0.024 \\
\hline & industry awareness & & $0.302^{* * *}$ & $0.248^{* * *}$ \\
\hline & research capacity & & $0.341^{* * *}$ & $0.311^{* * *}$ \\
\hline & teaching ability & & 0.278 & 0.265 \\
\hline & academic atmosphere & & 0.103 & 0.119 \\
\hline \multirow[t]{9}{*}{ Step 3} & basic quality $\times$ academic atmosphere & & & 0.049 \\
\hline & industry awareness $\times$ academic atmosphere & & & -0.059 \\
\hline & research capacity $\times$ academic atmosphere & & & $0.244^{* *}$ \\
\hline & teaching ability $\times$ academic atmosphere & & & 0.089 \\
\hline & $\mathrm{R}^{2}$ & 0.031 & 0.113 & 0.171 \\
\hline & Adjust $\mathrm{R}^{2}$ & 0.009 & 0.077 & 0.121 \\
\hline & $\triangle R^{2}$ & 0.032 & 0.079 & 0.048 \\
\hline & $\mathrm{F}$ & 1.401 & $3.103^{* *}$ & $3.433^{* * *}$ \\
\hline & $\triangle \mathrm{F}$ & 1.401 & $5.234^{* *}$ & $3.841^{*}$ \\
\hline
\end{tabular}

Note: ${ }^{*} \mathrm{P}<0.05,{ }^{* *} \mathrm{P}<0.01, n=218,{ }^{* * *} \mathrm{P}<0.001$

Table 3. Regulating role of academic atmosphere in the interaction between the competency and job performance

When the interactions between two of basic quality, teaching ability, industry awareness, research capacity, and academic atmosphere are incorporated into the performance regression 
equations, the interaction between teaching ability and academic atmosphere significantly increases the interpretative ability of regression equations $\left(\triangle R^{2}=0.048, P<0.001\right)$, which indicates that academic atmosphere can coordinate the interaction between research capacity and job performance, and this supports the assumptions Hc. The interaction between industry awareness and academic atmosphere cannot significantly increases the interpretative ability of performance regression equations, which indicates that academic atmosphere cannot coordinate the interaction between industry awareness and job performance, and this does not support the assumptions $\mathrm{Hb}$. Therefore, in general, academic atmosphere can coordinate the interaction between competency and job performance, which supports the assumptions $\mathrm{H}$.

Using hierarchical regression analysis, we found that academic atmosphere can coordinate the interaction between research capacity and job performance. In order to analyze the influence of academic atmosphere (regulated variable), we classified academic atmosphere into two types-good academic atmosphere and normal academic atmosphere, and compared them. When the value of academic atmosphere is $M+1 S D$, then it is good academic atmosphere, while the value of academic atmosphere is $M-1 S D$, then it is normal academic atmosphere. The results are summarized in Figure 2.

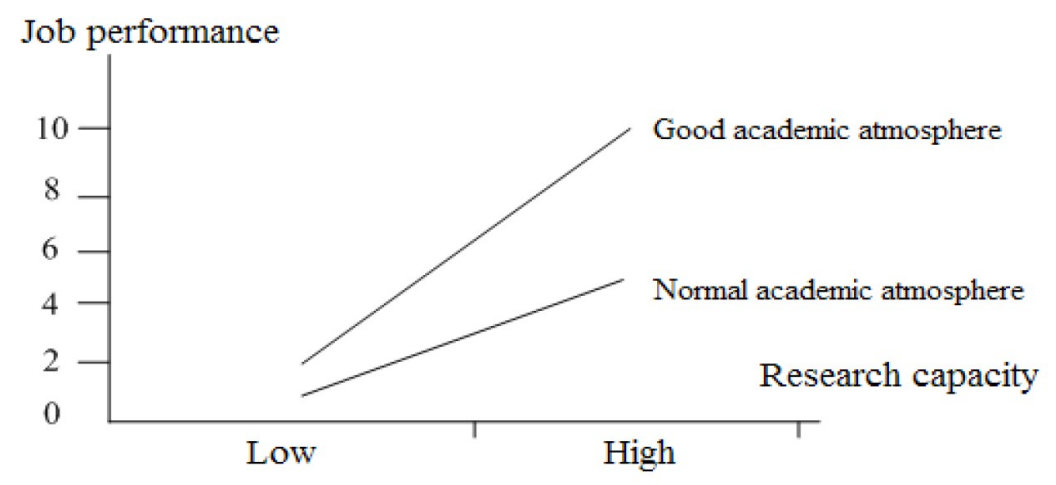

Figure 2. Coordination of academic atmosphere between research capacity and job performance

We found that if their research capacities equals, the job performance of the teachers in research universities with good academic atmosphere is better than that with normal academic atmosphere. And the increases of job performance in research universities with industry characteristics and good academic atmosphere will be higher than that with normal academic atmosphere. 


\section{Conclusion}

This paper proposed a university teachers' competency model for research universities with industry characteristics, examined the relationship between the competency and job performance, and investigated the influence mechanism of competency on job performance. We found that there exists a significant positive correlation between teaching performance, job performance, research performance, profession service performance and the teachers' competency level and each dimensions in research universities with industry characteristics. While the correlation between teaching performance and research capacity, between research performance and teaching ability, and between profession service performance and basic quality is positive, but not significant, which can help to select and train university teachers and plan vocational development for them. In addition, we also found that academic atmosphere plays a regulatory role in the interaction between the teachers' competency and job performance. Our findings can help to improve teaching staff construction and promote the development of research universities.

\section{References}

Armeli, S., Eisenberger, R., Fasolo P., \& Lynch, P. (1998). Perceived organizational support and police performance: The moderating influence of socioemotional needs. Journal of Applied Psychology, 83(2), 288-297. http://dx.doi.org/10.1037/0021-9010.83.2.288

Deng, W.L. (2009). Research on the academic atmosphere evaluation system. Master thesis. Central South University, Changsha.

Ma, W.H., Liu, J., \& Fan, J. (2012). Empirical Study on the Impact of University-Industry Cooperation on Academic Team Building: A Test of Regulating Effect of Team Heterogeneity. Journal of Industrial Engineering/Engineering Management, 26(2), 42-47.

Song, Q. (2008). Research on the relationship between college teachers' competency and job performance. Master thesis. Guangxi Normal University, Guilin.

Spencer, L.M., McClelland, D.C., \& Spencer, S. (1994). Competency assessment methods: History and state of the art. Boston: Hay-McBer Research Press.

Wang, C.M., \& Chen, M.K. (2002). Managerial competency modeling: a structural equation testing. Psychological Science, 25(1), 513-516.

Wen, Z.L., \& Hou, J.T. (2004). Structure equation model testing: cutoff criteria for goodness of fit indices and chi-square test. Psychological Science, 36(2), 186-194. 
Zhou, M.J. (2005). Organization, supervisory support, Organizational affective commitment and work outcomes. PhD. Thesis. Zhejing University, Hangzhou.

Journal of Industrial Engineering and Management, 2014 (www. jiem. org)

\section{(a)}

Article's contents are provided on a Attribution-Non Commercial 3. 0 Creative commons license. Readers are allowed to copy, distribute and communicate article's contents, provided the author's and Journal of Industrial Engineering and Management's names are included. It must not be used for commercial purposes. To see the complete license contents, please visit http://creativecommons. org/licenses/by-nc/3. 0/. 